\title{
Proposed new bacterial taxa and proposed changes of bacterial names published during 1994 and considered to be of interest to medical or veterinary bacteriology
}

\author{
W. FREDERIKSEN and J. URSING \\ Department of Clinical Microbiology, Statens Seruminstitut, Artillerivej 5, DK 2300 Copenhagen S, Denmark and \\ *Department of Medical Microbiology, Lund University, Malmö General Hospital, S-21401 Malmö, Sweden
}

At the meeting of the International Committee on Systematic Bacteriology (ICSB) in Prague, Czech Republic, in July 1994, the problems created by the publication of many new names and new combinations of names of both genera and species were discussed, provoked by a presentation by $\mathrm{Dr}$ J. T. Magee (Cardiff, UK). It was decided to establish an ad hoc committee within the ICSB with the task of formulating an approach to communication of new names to users in medical and veterinary bacteriology.

The following bacterial names have been published in 1994 in articles in the International Journal of Systematic Bacteriology (IJSB) (validly published) or published elsewhere and listed in 1994 on the validation lists in IJSB (validated). For some taxa there is

\section{Notes to the list}

Type means Type species of a new genus or Type strain of a species/subspecies.

Methods used means methods used for the taxonomic characterisation of the new taxa: 1, classical phenotypic characterisation; 2. chemotaxonomy, e.g., fatty acids, quinones; 3 . protein electrophoresis; 4. Guanine +Cytosine mol \%; 5. DNA-DNA hybridisation; 6. rRNA-DNA hybridisation; 7. rRNA sequence determination; 8. monoclonal antibodies; 9. ribotyping, REA-typing and similar; 10. enzyme electrophoresis.

gen. nov. means genus novum; nom. rev. means nomen revictum (revived name); comb. nov. means combinatio nova (new comb- a valid synonym; in these cases the old and the new name reflect different views on the classification of the taxon. The source of isolation-man or warm-blooded animals - has been the main criterion for selection. In some cases new species of clinically important genera have been included even if isolated from other sources.

The names are listed in the order in which they appeared in the IJSB. The number of names included on the list is $61, c .25 \%$ of the total number of new names published in 1994. We are aware that our selection is subjective, and that other delimitations could have been chosen. The intention is to publish a list once a year. The authors and the editors of the Journal of Medical Microbiology invite criticism and comments from readers.

ination); in most cases the names are names of new species, species nova (spec. nov.) or of new subspecies (subsp. nov.); IJSB, International Journal of Systematic Bacteriology; Scan JID, Scandinavian Journal of Infectious Diseases; JGM, Journal of General Microbiology; CCUG, Culture Collection University of Göteborg; ATCC, American Type Culture Collection; JCM, Japan Collection of Microorganisms; DSM, Deutsche Sammlung von Mikroorganismen; CIP, Collection Institut Pasteur; NCTC, National Collection of Type Cultures; CCM, Czechoslovak Collection of Microorganisms. 


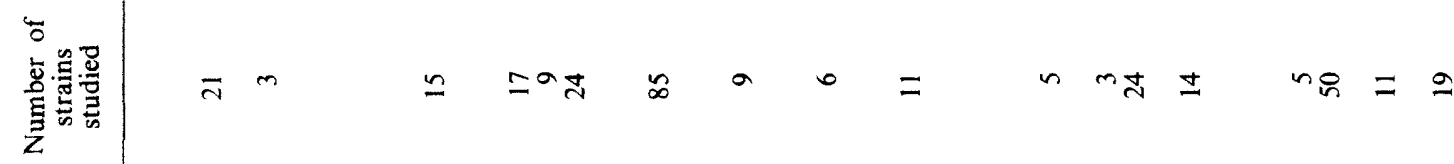

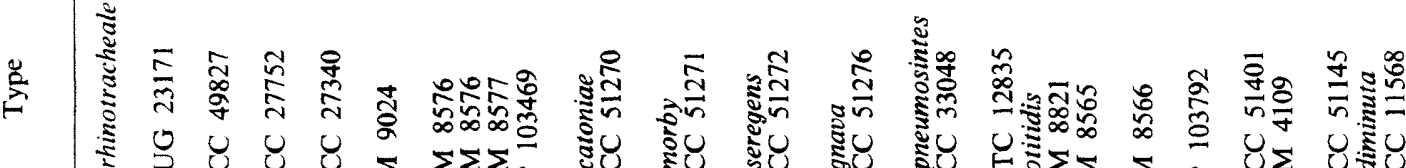
声

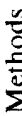

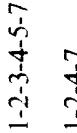

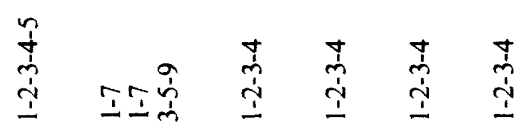

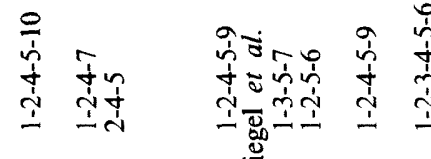

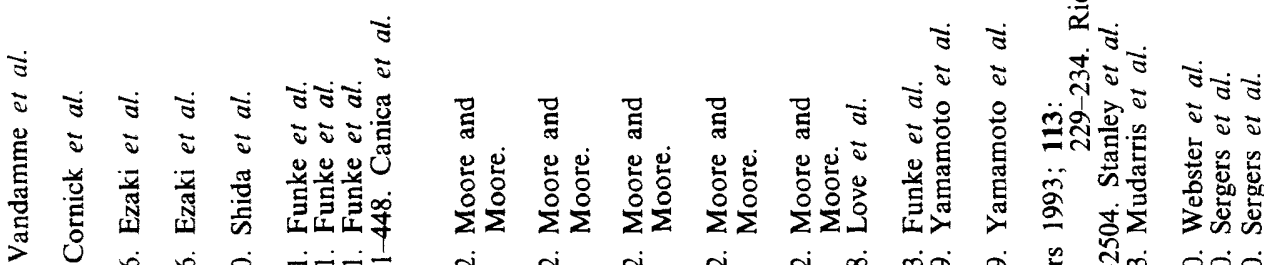

요

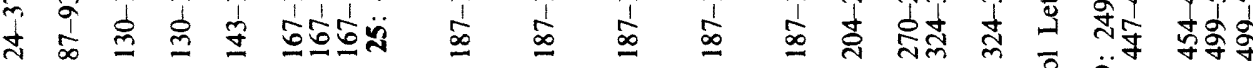

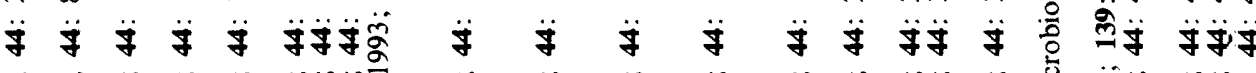

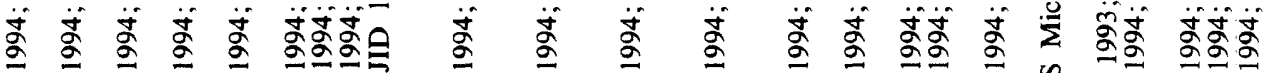

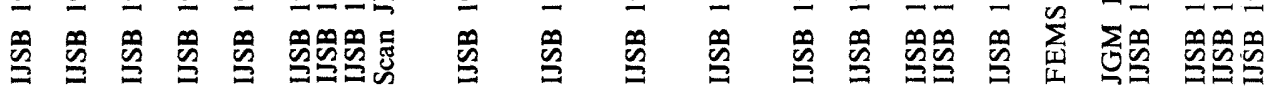

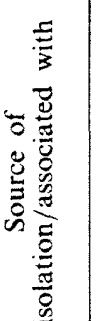

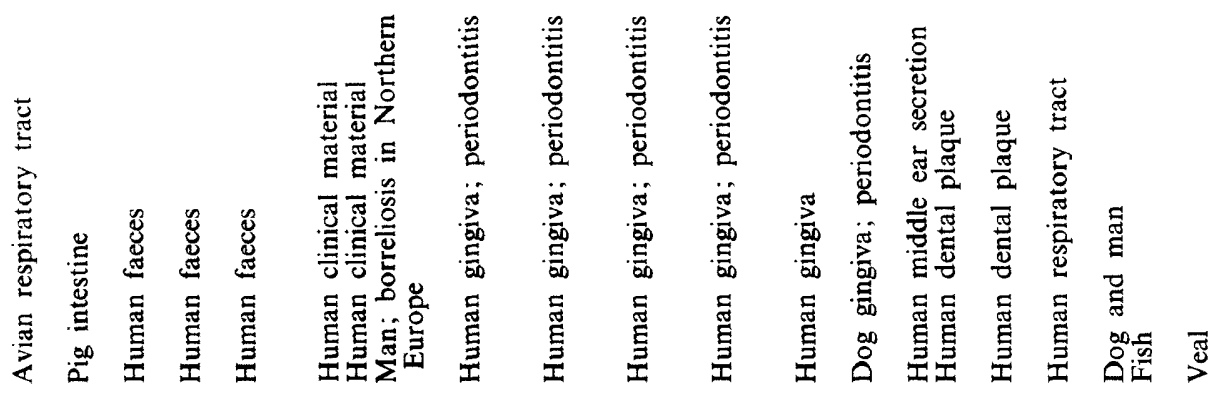

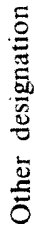

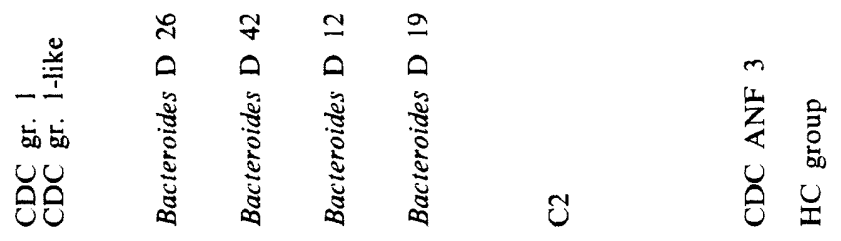

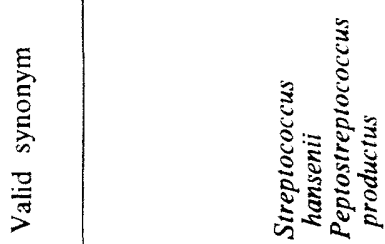

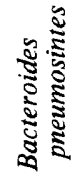

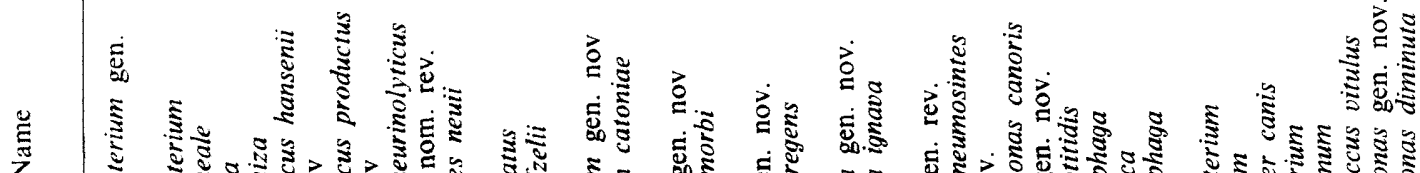

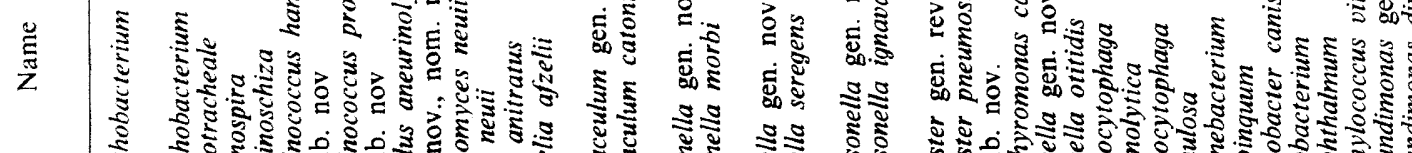


$90 \leadsto-\cos \approx \operatorname{tin}^{\circ}$

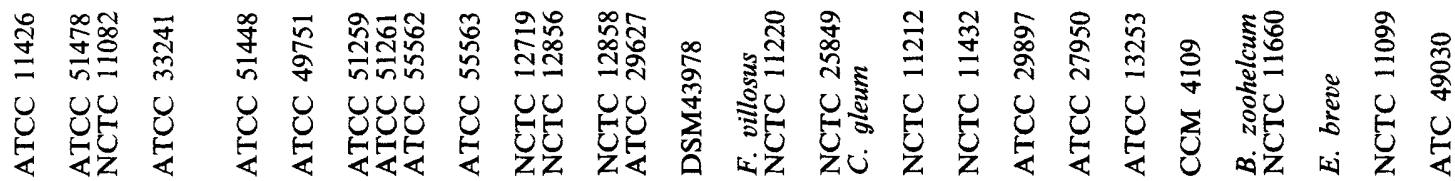

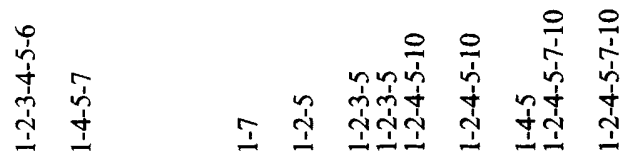

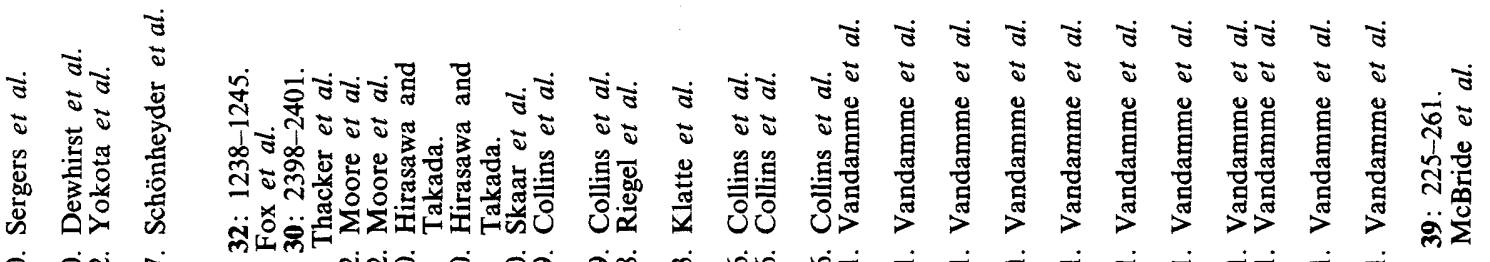

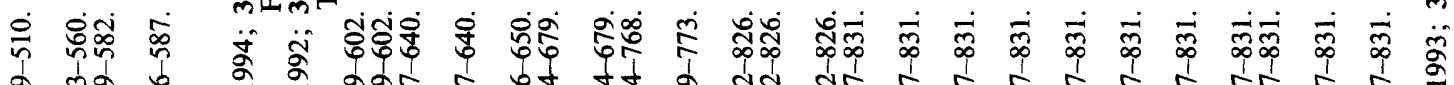

施

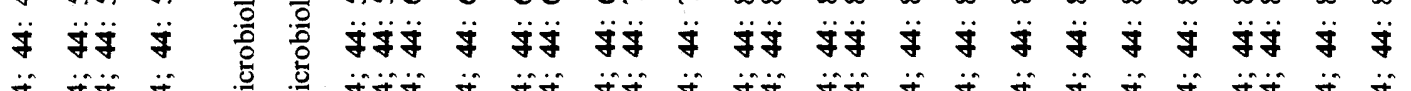

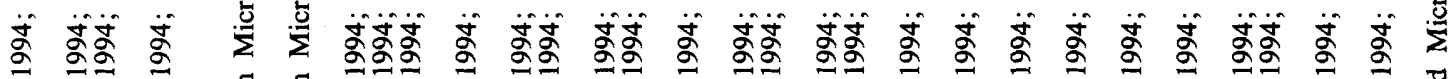

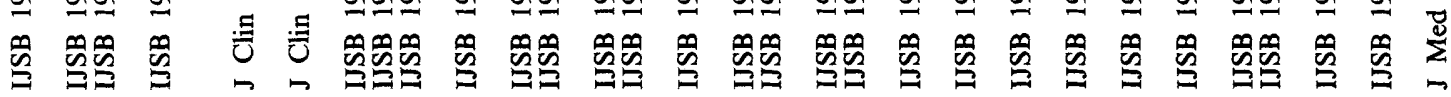

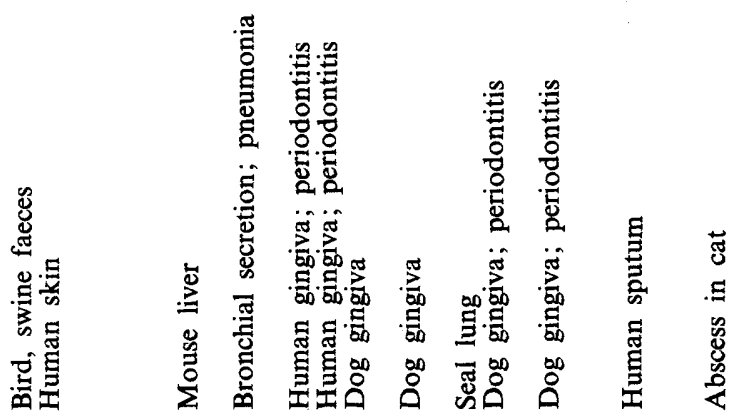

莺

ஸे

AD

:

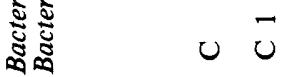

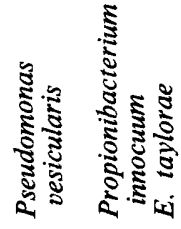
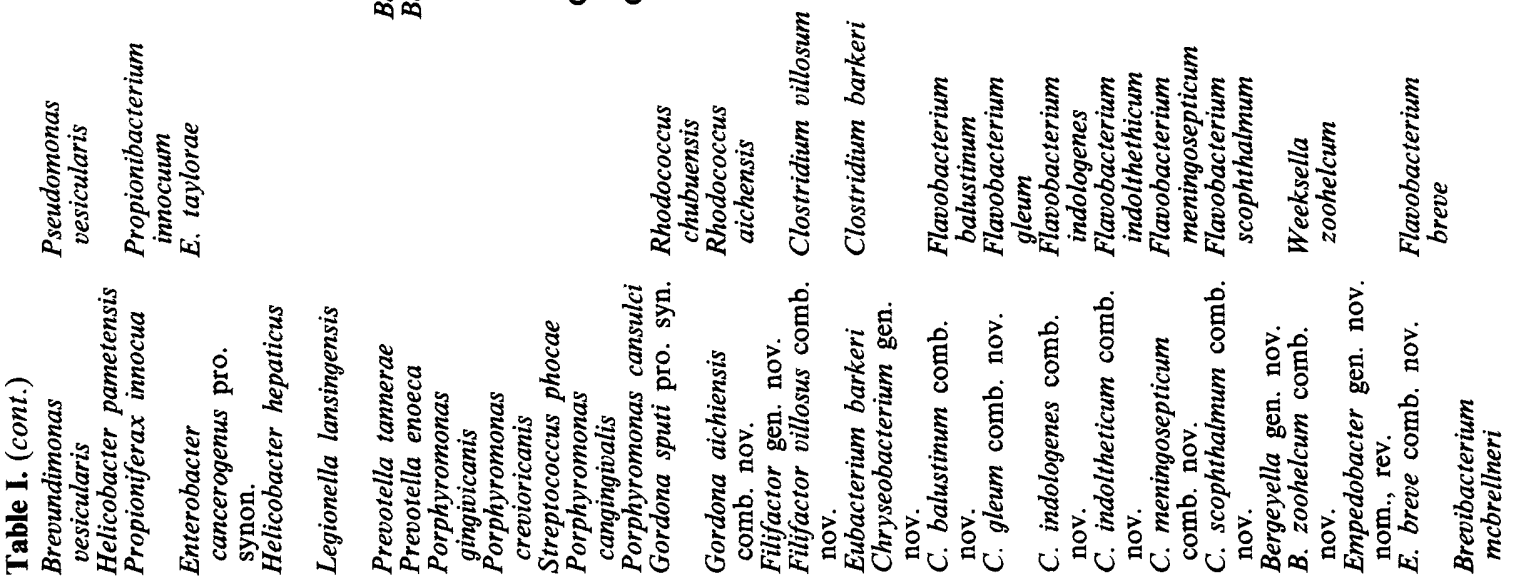